\title{
NEURAL NETWORKING OF INFILLED RC LOW-RISE SERVICE BUILDINGS
}

\author{
K. Abou El-Ftooh ${ }^{1}$, A. Seleemah ${ }^{2}$, A. Atta ${ }^{3}$, S. Taher ${ }^{4}$ \\ ${ }^{1}$ Ph.D. student, Faculty of Engineering, Tanta University, Egypt. \\ ${ }^{2}$ Professor of Structural Analysis, Faculty of Engineering, Tanta University, Egypt. \\ ${ }^{3}$ Associate Professor, Faculty of Engineering, Tanta University, Egypt. \\ ${ }^{4}$ Professor of Concrete Structures, Faculty of Engineering, Tanta University, Egypt.
}

\begin{abstract}
Artificial neural networks (ANNs) are one of the most research areas that attracts the attention of experts of various scientific areas. Recent research activities regarding ANNs indicated that this method is a powerful tool to solve complicated problems in engineering fields.

In this paper, ANNs were utilized to predict the lateral behavior of school buildings in Egypt. For this, reinforced concrete (RC) frames representing common school buildings with different characteristics were analyzed using nonlinear dynamic pushover analysis to obtain their capacity curves, failure loads and displacements. Parameters included number of stories, location and dimensions of the frames, distribution of masonry infill panels, and properties of concrete and reinforcement. Obtained data were used to train several ANN models with different topologies and learning algorithms. The most representative ANN was used to obtain more insight into the behavior of school building frames with different parameters.
\end{abstract}

KEYWORDS: Artificial Neural Networks, ANSYS, RC Frames, School buildings

\section{1-INTRODUCTION}

In the last decade, a wide range of research has been carried out on using Artificial Neural Networks (ANNs) for the purpose of analysis and design of structures. Recent research activities regarding ANN indicated that this method is a powerful tool to solve complicated problems in all engineering fields. ANN, similar to real human brain, has the ability to learn and utilize the acquired new experiences from past and similar affairs. This paper tries to utilize the power of ANN to predict the behavior of school building in Egypt taking into consideration the effect of presence or absence of infill panels in different bays.

Several previous studies have been conducted to investigate the effects of infill panels on frame behavior. For example, Amanat and Hoque (2006) studied the fundamental vibration periods for a series of regular RC framed buildings using 3D FE modeling and modal Eigen value analysis including the effects of infill. It has been found that when the frames do not include infill, as are modeled in conventional analysis, the period given by the analysis are significantly longer than the period predicted by the code equations justifying the imposition of upper limit on the period by the code. Anil and Altin (2007) investigated the behavior of ductile reinforced concrete (RC) frames strengthened by introducing partial infills under cyclic lateral loading. One-bay, one-story, 1/3 scale 
test specimens were constructed and tested under reversed cyclic loading. Test results indicated that partially infilled RC frames exhibited significantly higher ultimate strength and higher initial stiffness than the bare frame (frame with no infill).

ANNs were applied by some investigators to understand the behavior of frames. A statistical approach was proposed by Bakhary et al. (2007) to take into account the effect of uncertainties in developing an ANN model. By applying Rosenblueth's point estimate method verified by Monte Carlo simulation, the statistics of the stiffness parameters were estimated. The developed approach was applied to detect simulated damage in a numerical steel portal frame model and also in a laboratory tested concrete slab. Nikoo et al. (2012) studied a wall concrete frame with 4-stories and 4-bays, in nonlinear dynamic analysis for several records with different acceleration levels. The rate of total damage of the frame in each record and each acceleration were calculated, then the rate of damage were determined by using evolutionary ANN models. To determine the number of effective lag times and input data of earthquake in the ANN model, Cross-Correlation of time series was used. Korogl et al. (2012) studied the application of combined ANNs for the flexural capacity estimation of quadrilateral FRP confined reinforced concrete columns. A database on quadrilateral FRP confined RC columns subjected to axial load and moment was obtained from experimental studies in the literature. Lagaros and Papadrakakis (2012) proposed a new adaptive scheme in order to predict the structural non-linear behavior when earthquake actions of increased severity are considered. Sipos et al. (2013) analyzed infilled frames using ANNs trained on the experimental database that contains results of 113 published tests of one-story one-bay masonry infilled frames. In order to reduce the dimensionality of input data and achieve better performance of ANNs, dimensionality reduction techniques, principal component analysis, forward stepwise sensitivity analysis and dimensionless modeling parameter approach were applied. A multilayered back propagation ANN with adaptive weight function was applied and the optimal network topology, for each required output value, has been chosen.

This paper aims to give more insight into the behavior of school buildings of Egypt using ANNs. For this, RC frames representing common school buildings with different characteristics were analyzed using nonlinear dynamic pushover analysis to obtain their capacity curves, failure loads and displacements. Input parameters included number of stories, location of the frames, distribution of masonry infill panels, dimensions and reinforcement of the frame components (beams and columns) and properties of the concrete. Output parameters include the failure load and corresponding displacement of the frames. Obtained data were used to train several ANN models with different topologies and learning algorithms. The most representative ANN was used to give more insight into the behavior of school building frames with different parameters.

\section{2-DESCRIPTION OF THE MODEL}

Frame models that represent common school buildings were considered. Table (1) lists the main variables that are typically used in these buildings. The cases that include all the suggested variables listed in Table (1) are 16200 cases. After careful study of these cases, 10\% of these cases, namely 1620 cases, has been selected and analyzed using ANSYS 10 (2005). Selected cases were chosen such that they cover the whole domain of the problem. This is essential to give the ANNs the chance to "understand" the whole problem. Fig. 1.a illustrates the finite element models of interior and exterior frames taking into consideration the effect of transverse action for beams and slabs. Analyzed cases include frames with three, four, and five story with heights of $11.25,14.75$, and $18.25 \mathrm{~m}$, respectively. The height of the first story is $4.25 \mathrm{~m}$, and the heights of typical stories are 3.5 $\mathrm{m}$. The total width of the building is $8.0,9.5$ and $11.0 \mathrm{~m}$ (see Fig. 1). Infill masonry walls with thickness $\mathrm{t}_{\mathrm{w}}=0.125$ and $0.25 \mathrm{~m}$ were used. The beams of the frame $(\mathrm{B} 1, \mathrm{~B} 2)$ has depth $=0.5,0.6,0.7$ $\mathrm{m}$ and width $=0.25 \mathrm{~m}$. Typical reinforcement details of different frames are shown in Fig. 2 and Table 2. The material parameters was taken as follows: For concrete: compressive strength $\mathrm{F}_{\mathrm{cu}}=20$, 
27.5, $35 \mathrm{MPa}$, ultimate tensile strength $\mathrm{F}_{\mathrm{tu}}=2,2.75,3.5 \mathrm{MPa}$, Poisson's ratio v=0.2. Steel reinforcement was modeled using steel bar for the skeleton of frames (columns, and beams), but for transverse slabs or beams reinforcement, it was modeled as smeared steel. Steel modulus of elasticity $E_{s}=210 \mathrm{kN} / \mathrm{mm}^{2}$, steel yield strength $\mathrm{f}_{\mathrm{sy}}=360 \mathrm{MPa}$, yield strength of stirrups $=240 \mathrm{MPa}$ and Poisson's ratio $v=0.3$.

Different arrangement of masonry infill panels were analyzed (see Fig. 1-b). Such arrangements were chosen to represent different cases of existence of infill panels in these school buildings. Pushover analyses were conducted by applying a lateral triangle load on the left or the right sides of the frames. Results indicated that, when the triangular load was applied towards the longer span side, the frames exhibited less lateral load capacity. Hence, this direction for load application was selected to reveal the least lateral capacity of the frames.

\section{ANN LEARNING TECHNIQE}

After careful study of the literature, it was found that selected parameters listed in Table 1 are the most important parameters that affect the behavior of the frames. Therefore, eleven parameters were chosen as inputs. These are, Number of stories, Ns; Short span, S1; Long span, S2; Height of beam, $\mathrm{t}$; Thickness of column 2, $\mathrm{t} 2$; Thickness of column 3, $\mathrm{t} 3$; Strength of concrete, $\mathrm{f}_{\mathrm{cu}}$; Percentage of area of steel to balanced steel, $A_{s}$; Width of brick wall, $t_{w}$; Frame location (Interior or Exterior), I and E; and Configuration of frames, C. (refer to Fig.1.b).

The selected $1620 \mathrm{RC}$ buildings were analyzed. Output data from the nonlinear analysis were used in the training process of the ANN. For this, several Feed-forward, multi-layer, back-propagation ANNs were constructed to predict the base shear over total weight (B.S/T.W) and top displacement over total height (T.D/T.H).

The available data were split into four parts. These are: a) Training set, used to determine the network weights; b) Validation set, used to estimate the network performance and decide when training should stop; c) Testing set, used to verify the effectiveness of the stopping criterion; and d) Prediction set, used to verify the effectiveness of the stopping criterion and to estimate the expected performance in the future. After careful study of the recommendations in the literature, it was decided to use $50 \%, 35 \%, 10 \%$ and $5 \%$ of the available data for training, testing, cross validation and prediction, respectively. The flow chart shown in Fig. 3 summarizes the general layout for the training process that was used in the current study. Moreover, Fig. 4 shows typical structure of ANNs used in this study.

\subsection{Transfer functions and normalization of data}

A Sigmoid transfer function was used in this study. The equation of sigmoid function is given by

$$
f(t)=\frac{1}{1+\exp (-t n)}
$$

where $f(\mathrm{t})=$ transfer function, $n=$ net input of neuron, $t=$ an approximation representing the length of linear part of transfer function diagram. Data were normalized to be presented to the networks. A simple linear normalization function within the values from (0.1 to 0.9) is given by Eq. (2), (Arslan 2009 and Bakharyet al. 2007).

$$
S X=0.1+0.8\left(\frac{X-X \min }{X \max -X \min }\right)
$$


Where $S X$ is the normalized value of variable $X$ and $X \min$ and $X \max$ are the corresponding minimum and maximum values of the same variable, respectively.

\subsection{Criteria for assessing model performance}

One of the criteria used for assessing the performance of the ANNs is the coefficient of multiple determinations $\left(R^{2}\right)$. In addition, the mean square error $(M S E)$ has also been used to assess the model performance. The equations of these criteria are as follows

$$
\begin{aligned}
& R^{2}=1-\frac{\sum_{i=1}^{n}\left(x_{o}-x_{p}\right)^{2}}{\sum_{i=1}^{n}\left(x_{0}-x_{o}^{\prime}\right)^{2}} \\
& M S E=\frac{\sum_{i=1}^{n}\left(x_{o}-x_{p}\right)^{2}}{n}
\end{aligned}
$$

Where $x o$ is the actual value of $x i$ with $i=1,2, \ldots, n$ observations, $x o^{\prime} \square$ is the average of $x i, x p$ is the predicted values of $x i$, and $n$ is the total number of observations.

\subsection{ANNs}

\section{Type and architecture}

In the current study, different types of neural networks were used. These are the Generalized Feed Forward (GFF), General Recurrent (GR), Multilayer Perceptron (MP) and Principal Component Analysis (PCA) networks. In each type of these networks, different learning functions have been utilized. These are the Momentum (M), Quick-propagation (Q), and the Conjugate Gradient (CG) learning functions.

Several networks with one or two hidden layers including 5 to 100 neurons per hidden layer were constructed, trained and tested such that the optimum neural network can be selected to predict the behavior of the frames. Input layer included eleven nodes representing the number of stories, Ns; first and second spans of the two bay frame, $S 1$ and $S 2$, respectively; dimensions of the three columns of the frame, $t_{1}, t_{2}$ and $t_{3}$, respectively; concrete compressive strength, $\mathrm{f}_{\mathrm{cu}}$; area of main steel of beam, $A_{s}$; thickness of the infill panel wall, $t_{w}$; location of the frame, Interior, I or Exterior, $E$, respectively; and distribution of infill panels in the frames, $\mathrm{C}$ (Refer to Fig.1-b). Output layer included two nodes representing (B.S/T.W) and (T.D/T.H).

\section{SELECTION OF APPROPRIATE NETWORK}

Figs. 5 to 8 show the results of the MSE for base shear over total weight and top displacement over total height for different networks and different learning functions. Moreover, Table 3 shows the performance of some selected networks in terms of both $M E S$ and $R^{2}$.

It is clear that while the performance of the GFF networks is better when using two hidden layers, the performance of the GR and the MP networks is better when using only one hidden layer. For the PCA networks, comparable behavior is observed for the networks having one or two hidden layers. For GFF, GR, and MP networks, the CG learning rule gives best results while this behavior is not clear for the PCA networks. Also, increasing the number of processing elements per hidden layer does not necessarily mean better capturing of the actual performance. 
To Judge on the behavior of all networks and select the network with the best performance, one should keep in mind that the most successful network is the smallest size network that gives least errors for both target outputs not only during the training phase, but also during testing and cross validation phases. After careful study, it was found that network (MP-CG-11-15-2) which has one hidden layer containing 15 processing elements seems to be the most appropriate network for prediction of both base shear and top displacement.

Fig. 9 illustrates values of (B.S/T.W) and (T.D/T.H) obtained using finite element method FEM against those predicted by the selected ANN (MP-CG-11-15-2). Moreover, the line of equality is plotted on each figure. It can be seen that most ANN results lye on or very close to the line of equality indicating success of the selected ANN to predict the actual behavior not only during training phase but also during testing and cross validation phases.

The sensitivity analysis technique was used for monitoring the effect of deferent variables influencing the behavior of infilled RC frames and the results are shown in Figure 10. It is clear that the number of stories of the structure NS has a major effect on the (B.S/T.W) and a more pronounced effect on the (T.D/T.H). The concrete strength, $\mathrm{f}_{\mathrm{cu}}$, has a moderate effect on both the (B.S/T.W) and the (T.D/T.H). The steel area, $A_{s}$, has also a moderate effect on the (T.D/T.H) and a less effect on the (B.S/T.W). This might be attributed to the fact that all the studied cases has area of steel equal or less than the balanced steel area which means that different steel areas essentially means different deformability of the sections rather than different carrying capacity. Finally, the distribution of infill panels within the frames has a significant effect on the results in terms of both (B.S/T.W) and (T.D/T.H).

\section{EFFECT OF VARIOUS PARAMETERS ON THE RESPONSE OF RC INFILLED FRAMES}

To gain an insight into the effect of each parameter on the global behavior of infilled RC frames, the successful neural network (MP-CG-11-15-2) has been selected and used to estimate the response of different RC frames to variations in each parameter. Results will be presented and discussed in this section. Such results help engineers to understand the effect of each individual parameter on the general behavior of such complicated structures.

\subsection{Effect of Concrete Strength}

The effect of concrete strength, $\mathrm{f}_{\mathrm{cu}}$ has been predicted using ANNs. Figure (11) illustrates the capacity curves for concrete strength with base shear and top displacement for three, four and five story frames, with different configurations. Also, calculated values using FEM are also plotted on the same figures to examine the accuracy of the prediction of the ANN. It is observed that, in all cases the base shear increases linearly when increasing the concrete strength, $\mathrm{f}_{\mathrm{cu}}$. This is combined by a favorable behavior of more or less linear reduction of the top story displacement. This pronounced effect of concrete strength on the capacity of the frames can help the designer to significantly control the expected response. Lastly, the predictions of the ANN are observed to be in good agreement with the FE results.

The shear capacity, displacement and inter-story drift distribution over building height is compared for the case when $f_{c u}=27.5 \mathrm{MPa}$ and the results are shown in Fig. 12. It is clear from the figures that Configuration $\mathrm{C} 1$ which has no infill panels (bare frame) has the least stiffness and resistance and accordingly, exhibits very limited shear capacity. For the cases with infill panels, base shear changes dramatically with the configuration of the infill panels. For different number of stories, configurations C2 gives the highest stiffness of the buildings and accordingly, the highest shear capacity and lowest top displacement. Configuration $\mathrm{C} 3$ gives moderate stiffness of the buildings and hence moderate shear capacity and top displacement. Configurations C4 and C5 are characterized by 
open ground story which affects buildings' stiffness and strength distribution with height and give comparable results of both limited shear capacity combined with high top displacement and high ground story drift.

\subsection{Effect of Steel Ratio}

The effect of steel ratio (steel area over balanced steel area) was predicted using ANN. Fig. 13 illustrate the predicted base shear and top displacement against the steel ratio for cases of three, four and five story frames.

It can be observed that the base shear significantly increased with the existence of infill panel walls. It reached its maximum when the frame is completely infilled (case C2). Moreover, cases C4 and C5 had no significant difference. While in case the bare frame, $\mathrm{C} 1$, exhibited the lowest base shear over weight ratio. These results confirm that, presence of infill significantly affects the lateral behavior of $\mathrm{RC}$ frames due to the significant increase of both stiffness and strength provided by the infill. This behavior should be taken into account during the analysis of such structures.

It is also evident that the base shear linearly increase and the top displacement linearly decrease with increasing the steel ratio for all cases of frames. This beneficial effect of the steel gives the designer another tool to control the structural response. Again the results obtained using FE analysis lie very close to the results predicted using ANN indicating success of the ANN to predict the effect of steel on the lateral behavior of the frames.

\subsection{Effect of wall thickness}

While many design engineers consider the infill panels as non-structural elements and take their weight into account, it has been confirmed that the presence of infills in reinforced concrete frames can substantially change the seismic response of buildings. In certain cases they may produce undesirable effects or in other cases they can produce favorable effects of increasing the seismic resistance capacity of the building. The effect of wall thickness $\left(t_{\mathrm{w}}\right)$ has been investigated using the successful ANN. Figure (14) illustrates the relation between the wall thickness versus the base shear and top displacement for three, four and five story frames, with different configurations. It is evident that increasing the wall thickness results in a linear increase in the base shear for all cases. It also results in a general reduction of the top story displacement up to a thickness of $200 \mathrm{~mm}$ where a plateau is reached.

\section{CONCLUSIONS}

- The performance of the GFF networks is better when using two hidden layers while the performance of the GR and the MP networks is better when using only one hidden layer.

- For the PCA networks, comparable behavior is observed for the networks having one or two hidden layers.

- For GFF, GR, and MP networks, the CG learning rule gives best results.

- Increasing the number of processing elements per hidden layer does not necessarily mean better capturing of the actual performance.

- Network (MP-CG-11-15-2) which has one hidden layer containing 15 processing elements was observed to be the most appropriate network for prediction of both base shear and top displacement.

- The number of stories of the structure NS has a major effect on the (B.S/T.W) and a more pronounced effect on the (T.D/T.H).

- The concrete strength, $f_{\mathrm{cu}}$, has a moderate effect on both the (B.S/T.W) and the (T.D/T.H). 
- The steel area, $A_{s}$, has also a moderate effect on the (T.D/T.H) and a less effect on the (B.S/T.W).

- Presence of infill significantly affects the lateral behavior of RC frames due to the significant increase of both stiffness and strength provided by the infill.

- Configuration $\mathrm{C} 1$ which has no infill panels (bare frame) has the least stiffness and resistance and accordingly, exhibits very limited shear capacity. Due to this limited shear capacity, the top displacements also exhibit limited values.

- Configurations C2 gives the highest stiffness of the buildings and accordingly, the highest shear capacity and lowest top displacement.

- Configuration C3 gives moderate stiffness of the buildings and hence moderate shear capacity and top displacement.

- Configurations C4 and C5 are characterized by open ground story which affects buildings' stiffness and strength distribution with height and give comparable results of both limited shear capacity combined with high top displacement.

- The base shear increases linearly when increasing the concrete strength, $\mathrm{f}_{\mathrm{cu}}$. This is combined by a favorable behavior of more or less linear reduction of the top story displacement.

- The base shear linearly increase and the top displacement linearly decrease with increasing the steel ratio for all cases of frames.

- Increasing the wall thickness results in a linear increase in the base shear for all cases. It also results in a general reduction of the top story displacement up to a thickness of $200 \mathrm{~mm}$ where a plateau is reached.

\section{References}

[1] Amanat K. M., Hoque E., 2006, "A rationale for determining the natural period of RC building frames having infill", Engineering Structures, Vol.28, pp. 495-502.

[2]Anil, O., and Altin, S., 2007, "An experimental study on reinforced concrete partially in-filled frames", Engineering Structures, V. 29, pp. 449-460.

[3]ANSYS Version 10.0, 2005, User's and Theory Reference Manual.

[4]Arslan M. H., 2009, "Application of ANN to evaluate effective parameters affecting failure load and displacement of RC buildings", Natural Hazards and Earth System Sciences., Vol.9, pp. 967-977

[5]Bakhary N., Hao H., and Deeks, A. J., 2007, "Damage detection using artificial neural network with consideration of uncertainties", Engineering Structures, Vol. 29, pp. 2806-2815.

[6]Inel M., 2007, "Modeling ultimate deformation capacity of RC columns using artificial neural networks", Engineering Structures Vol. 29, pp. 329-335.

[7] Korogl M. A., Ceylan M., Arslan M. H. and Ilki A., 2012,"Estimation of flexural capacity of quadrilateral FRP-confined RC columns using combined artificial neural network", Engineering Structures, Vol.42, pp. 23-32.

[8] Kwan, A. K. H. and Zhao, Z. Z., (2002),"Cyclic Behaviour Of Deep Reinforced Concrete Coupling Beams", Proceedings Of The Institution Of Civil Engineers: Structures And Buildings Vol. 152, pp. 283-293.

[9] Lagaros N. D. and Papadrakakis M., 2012,"Neural network based prediction schemes of the nonlinear seismic response of 3D buildings", Journal of Advances in Engineering Software, Vol.44, pp. $92-115$.

[10]NeuroSolutions Version 5.07, 2005, User's and Theory Reference Manual.

[11]Nikoo M., Zarfam P. and Nikoo M., 2012, "Determining Displacement in Concrete Reinforcement Building using Evolutionary Artificial Neural Networks", World Applied Sciences Journal, Vol.12, pp. 1699-1708. 
[12]Saghafi B., Hassani A., Noori R., and Bustos M., 2008, "Artificial Neural Networks and Regression Analysis for Predicting Faulting in Jointed Concrete Pavements Considering Base Condition", International Journal of Pavement Research and Technology, Vol.2(1), pp.20-25

[13]Sipos T. K., Sigmund V. and Marijana H., 2013, "Earthquake performance of infilled frames using neural networks and experimental database", Engineering Structures, Vol. 51, pp. 113-127. 


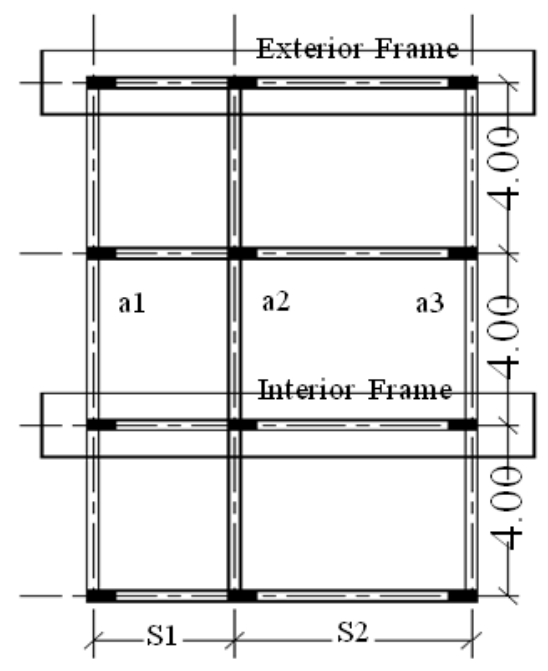

Frames location

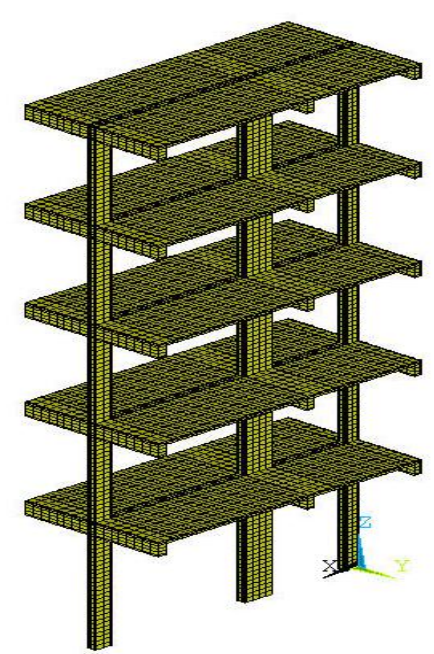

Interior (I) frame

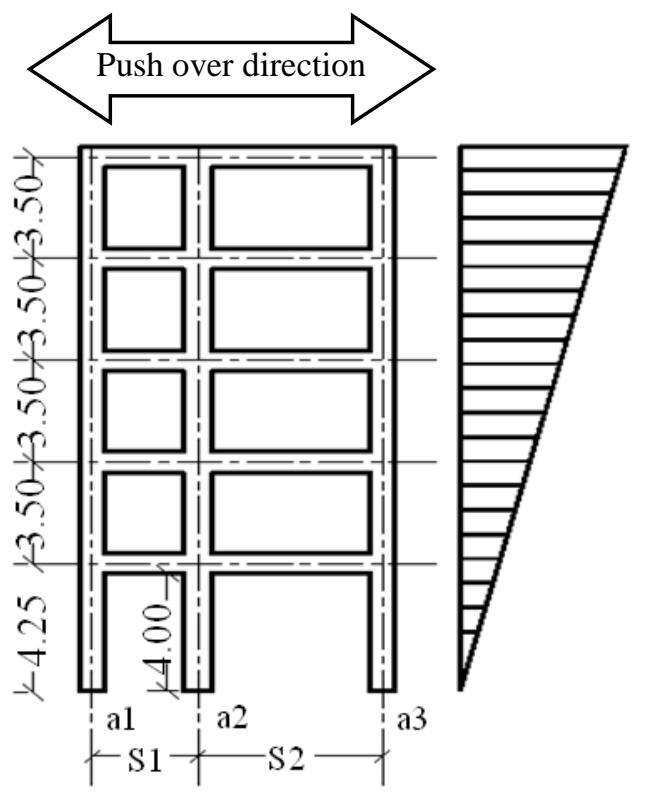

Applied load

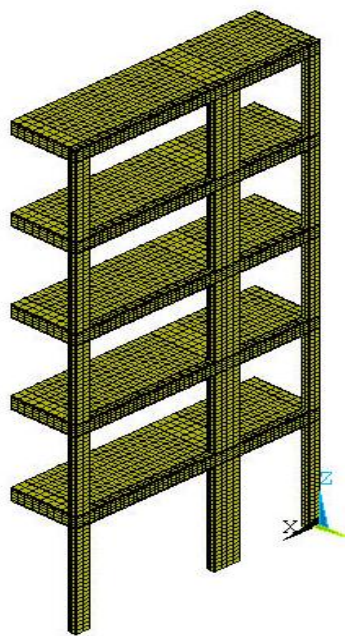

Exterior (E) frame

Fig. 1.a Frames location, Finite element mesh and loading

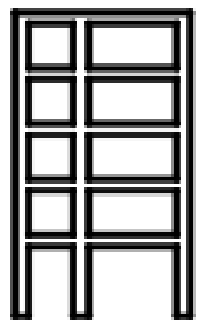

$\mathrm{Cl}$

\begin{tabular}{|c|c|}
\hline$\overline{7}$ & 号票 \\
\hline 国! & 돋몸 \\
\hline 軍豆 & 号金 \\
\hline 国톨 & 폳ㅁㅁㅁ \\
\hline 물ㄹㅁㄹ & 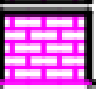 \\
\hline
\end{tabular}

$\mathrm{C} 2$

\begin{tabular}{|c|c|}
\hline & 둗고 \\
\hline & 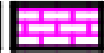 \\
\hline 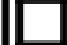 & 医要 \\
\hline & 匞胥 \\
\hline & 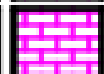 \\
\hline
\end{tabular}

$\mathrm{C} 3$

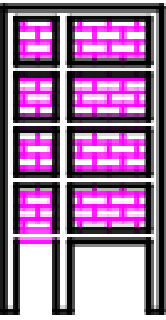

C4

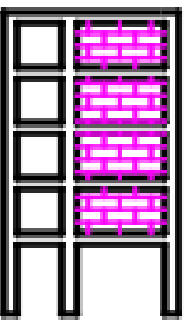

C5

Fig.1.b Distribution of infill panels within the frames

Fig.1.b Distribution of infill panels within the frames. 


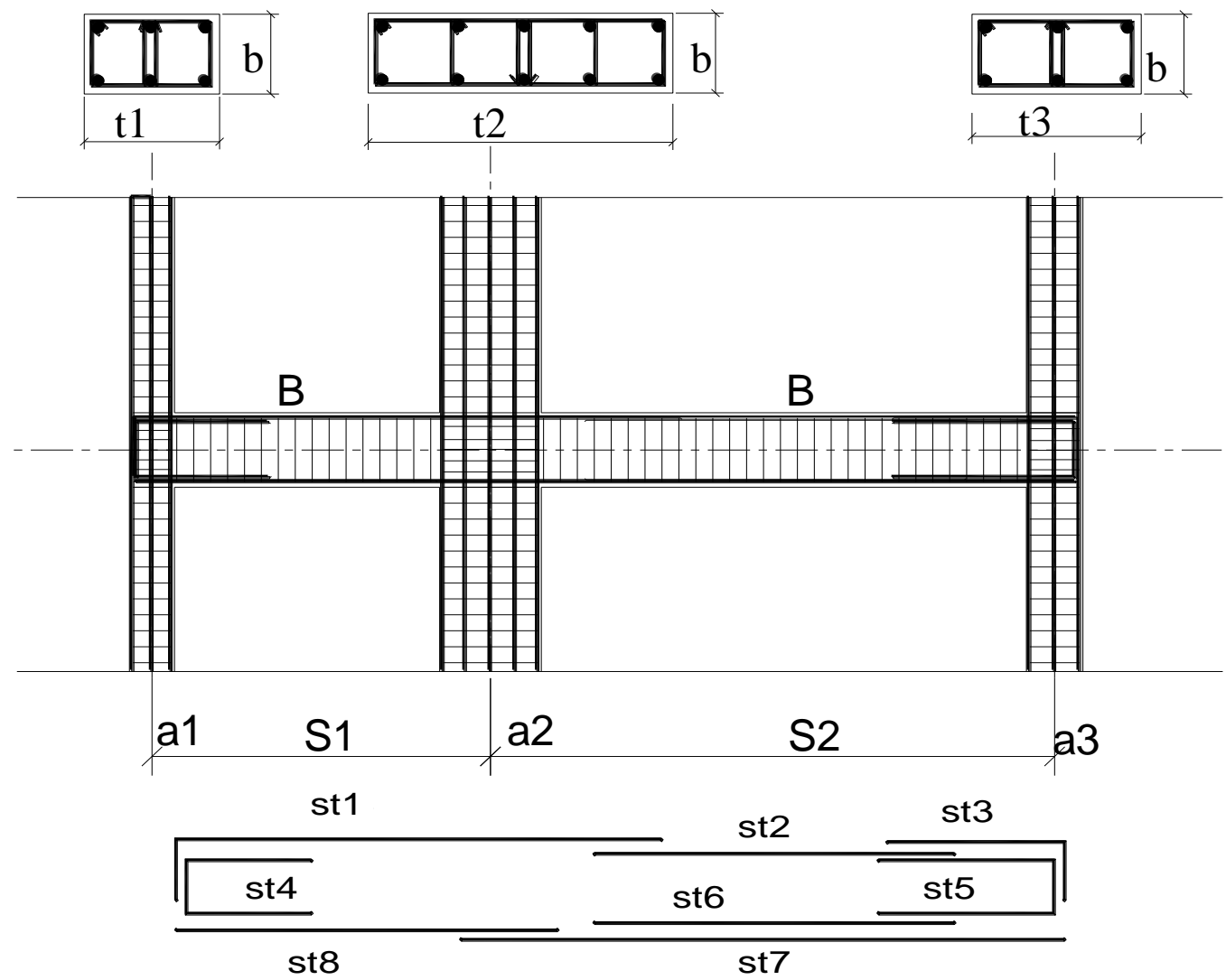

Fig. 2 Typical reinforcement details of frames

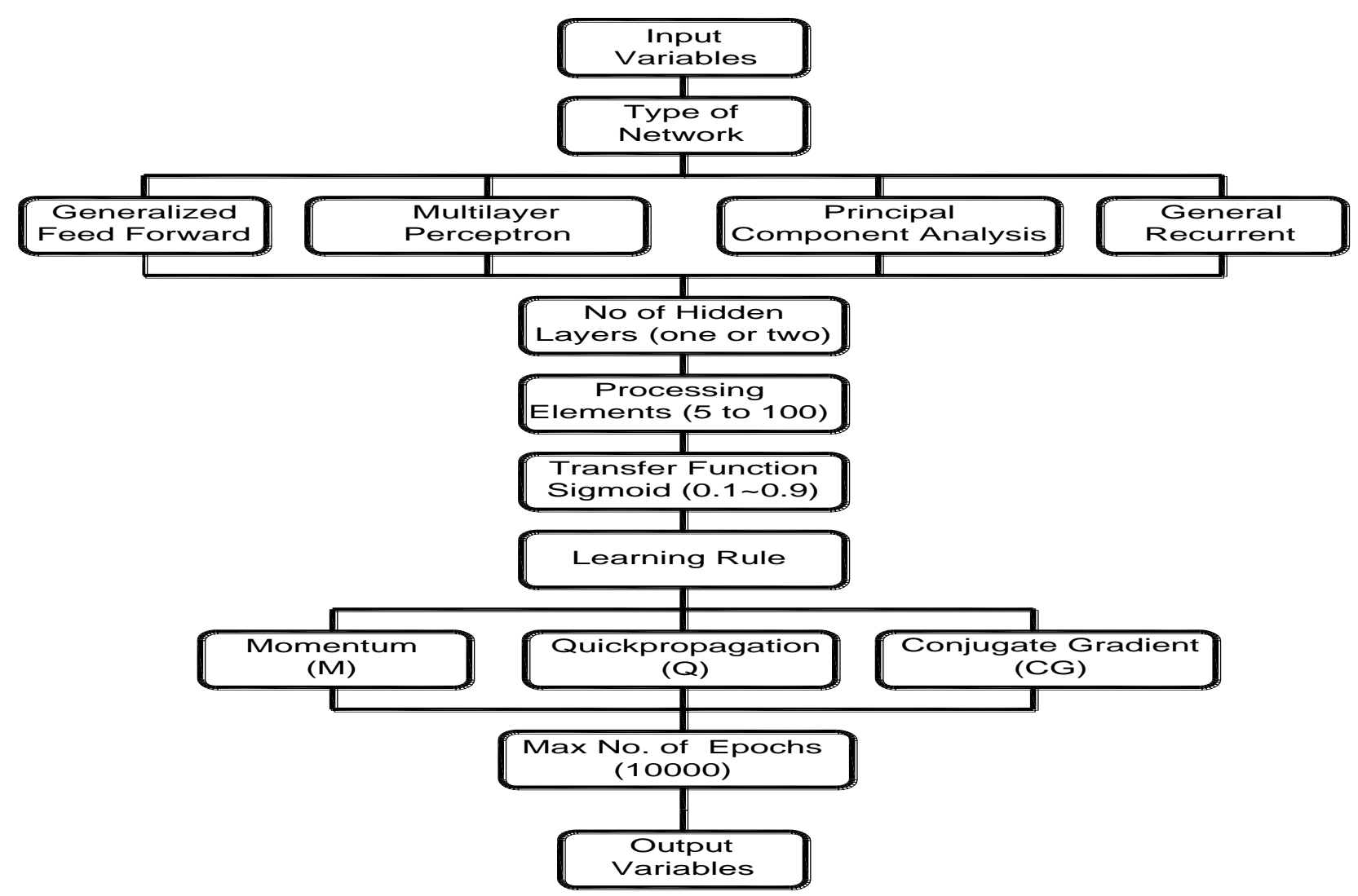

Fig. 3 Flow chart of ANN learning technique 


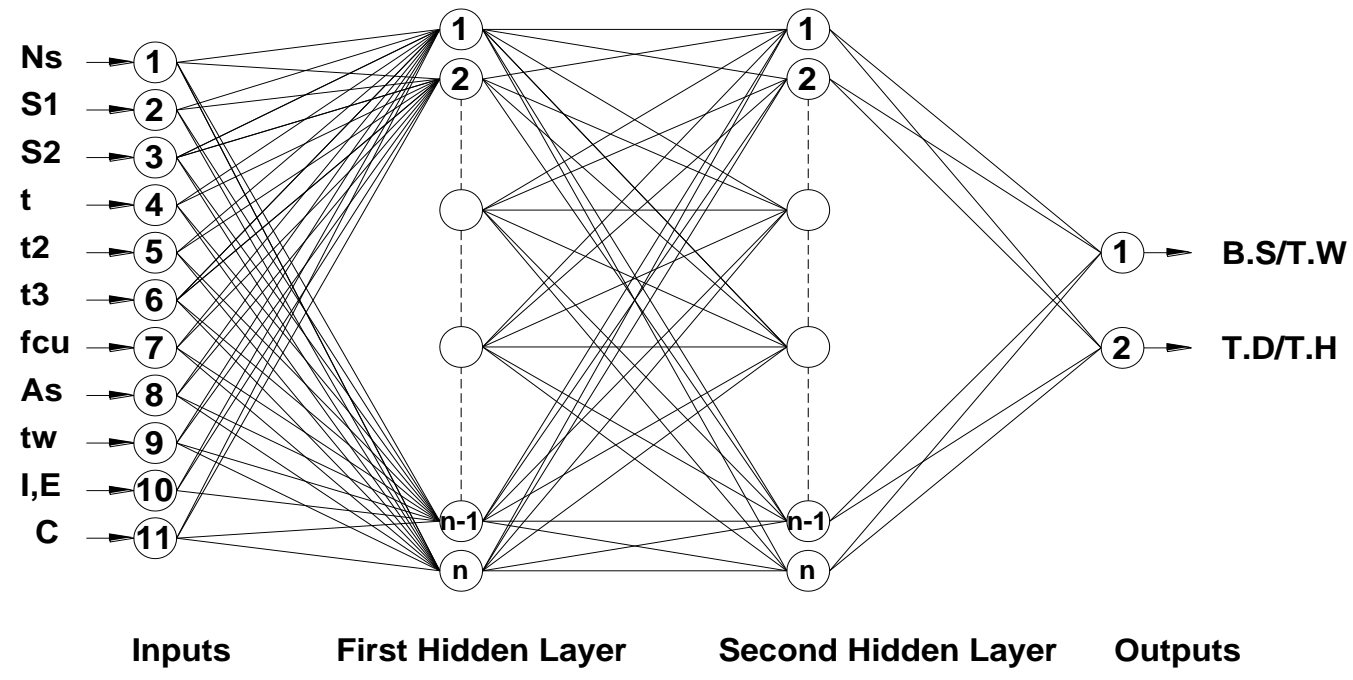

Fig. 4 Network consisting of an input layer, hidden layers, and output layer

\begin{tabular}{|lll|}
\hline$\cdots \cdots$ Training data (GFF-M) & $\cdots \cdots$ Testing data (GFF-M) & $\cdots$ Cross Validation data (GFF-M) \\
$\rightarrow-$ Training data (GFF-CG) & $\rightarrow-$ Testing data (GFF-CG) & $\longrightarrow$ Cross Validation data (GFF-CG) \\
$-\infty-$ Training data (GFF-Q) & $-\square-$ Testing data (GFF-Q) & $-\triangle$ Cross Validation data (GFF-Q) \\
\hline
\end{tabular}
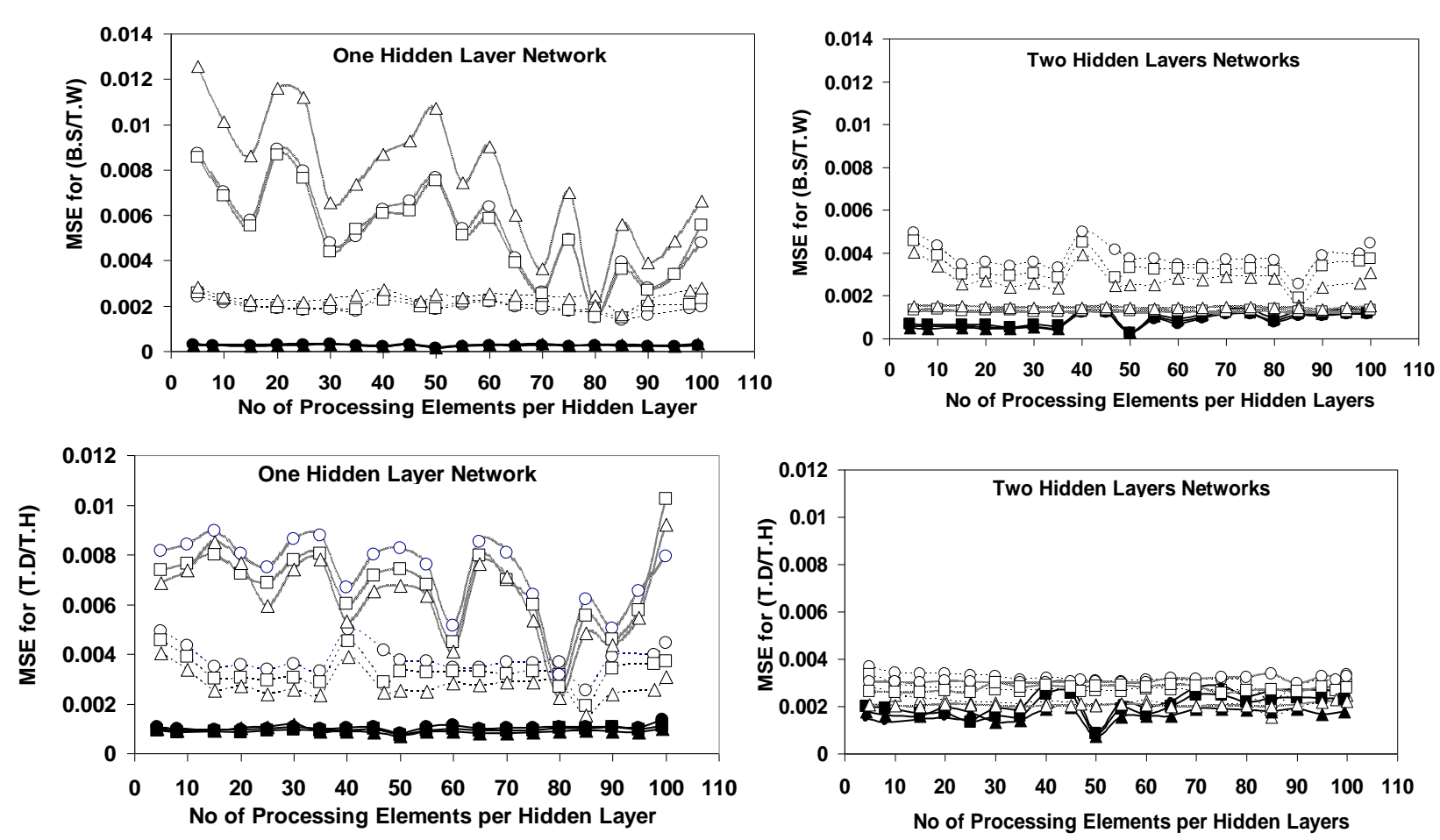

Fig. (5) Generalized Feed Forward Networks (GFF). 


\begin{tabular}{|lll|}
\hline$\cdots \circ \cdots$ Training data (GR-M) & $\cdots \cdots$ Testing data (GR-M) & $\cdots$ Cross Validation data (GR-M) \\
$\rightarrow-$ Training data (GR-CG) & $\rightarrow-$ Testing data (GR-CG) & - Cross Validation data (GR-CG) \\
$-\square-$ Training data (GR-Q) & $-\square$ Testing data (GR-Q) & $-\triangle$ Cross Validation data (GR-Q) \\
\hline
\end{tabular}
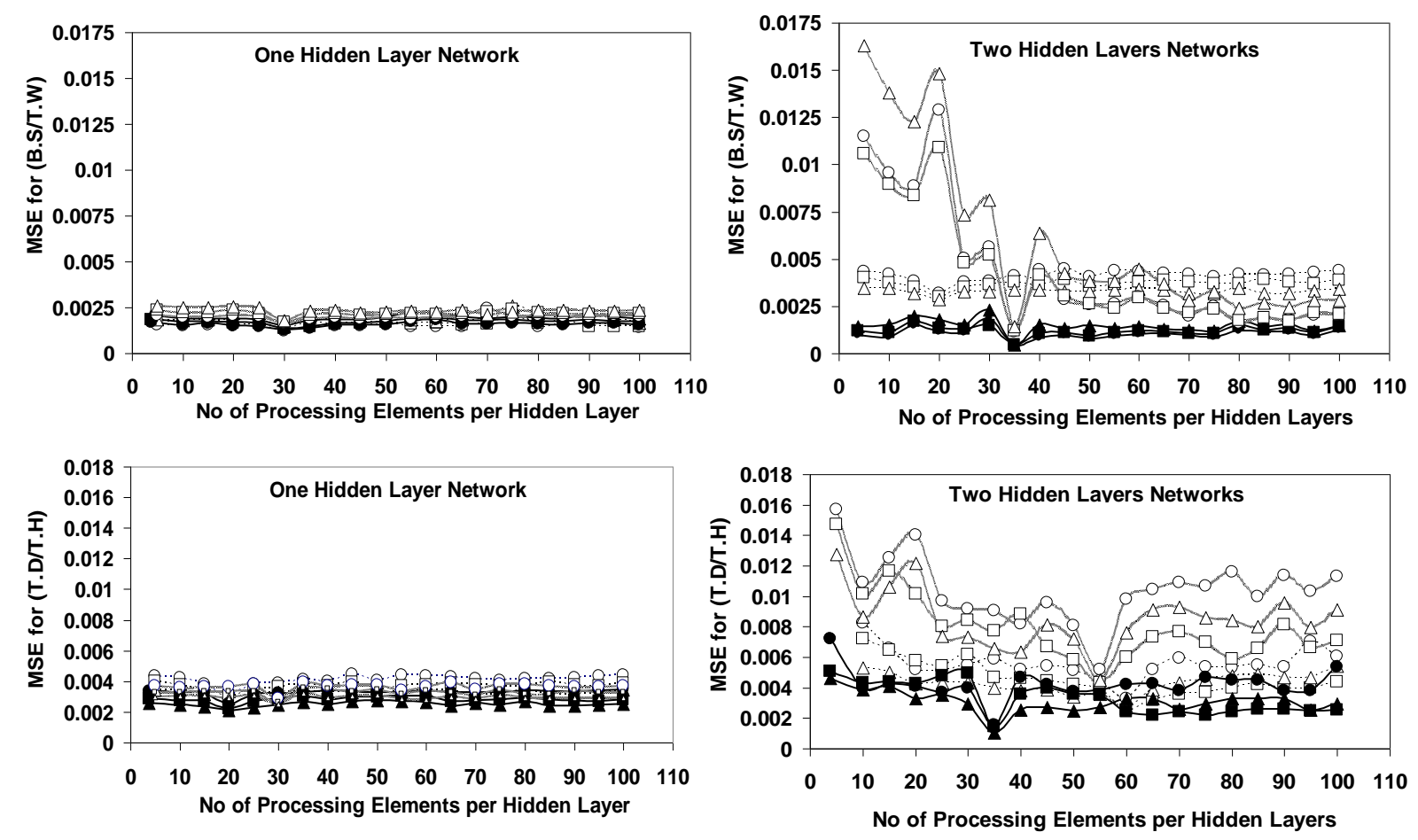

Fig. (6) General Recurrent Networks (GR).

\begin{tabular}{|c|c|c|}
\hline ‥- - Training data (MP-M) & $\cdots \square \cdots$ Testing data (MP-M) & $\Delta \cdots$ Cross Validation data (MP-M) \\
\hline$\longrightarrow$ - Training data (MP-CG) & $\rightarrow-$ Testing data (MP-CG) & $\longrightarrow$ Cross Validation data (MP-CG) \\
\hline$=0=$ Training data (MP-Q) & $\ldots-$ Testing data (MP-Q) & $\triangle \cdots$ Cross Validation data (MP-Q) \\
\hline
\end{tabular}
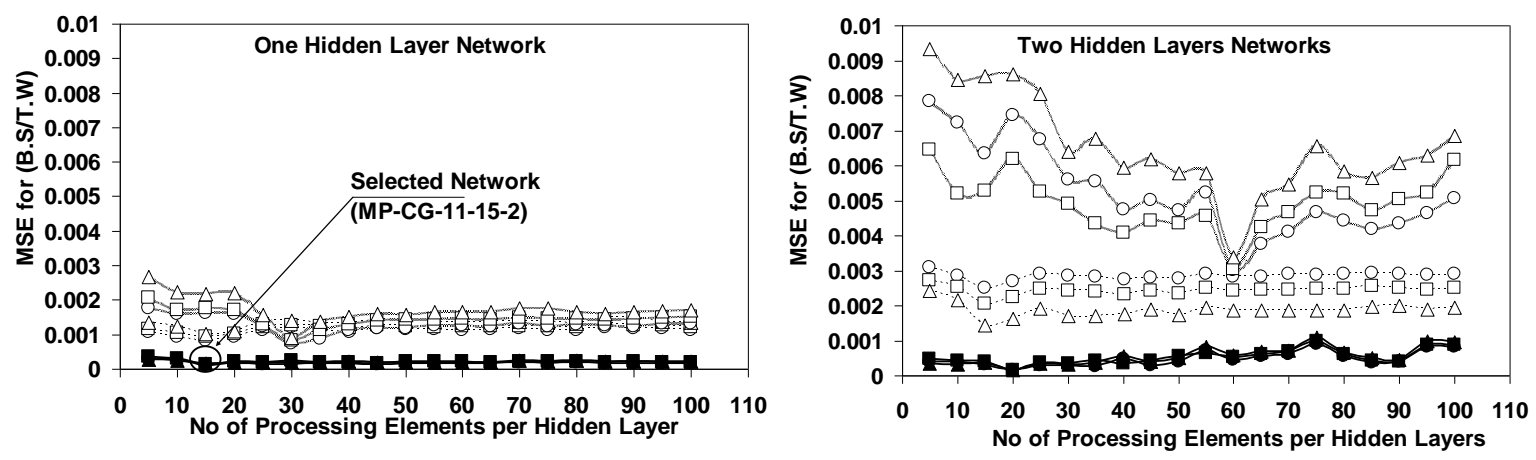

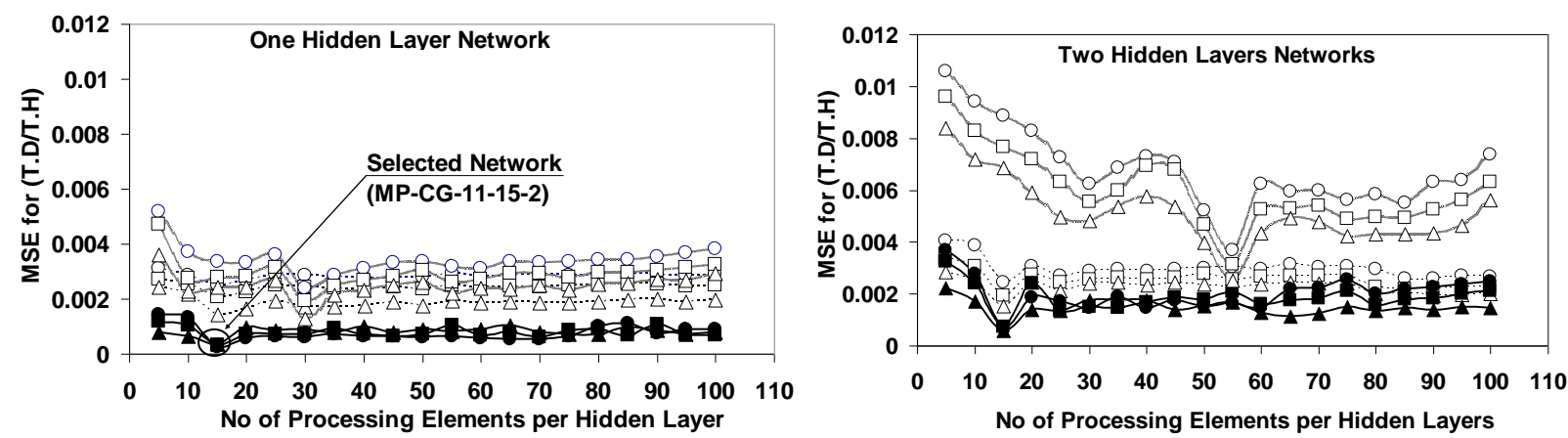

Fig. (7) Multilayer Perceptron Networks (MP).
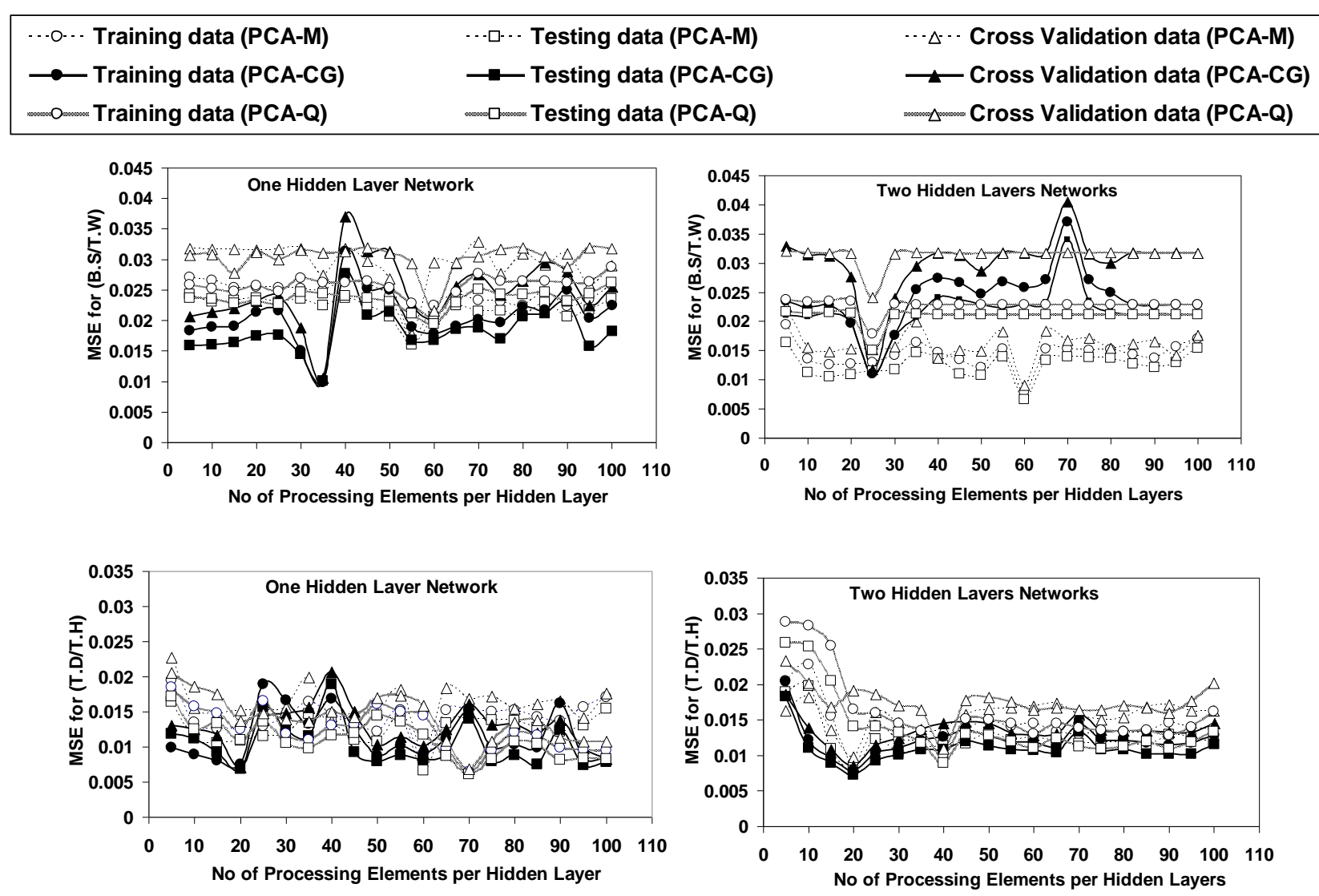

Fig. (8) Principal Component Analysis Networks (PCA)
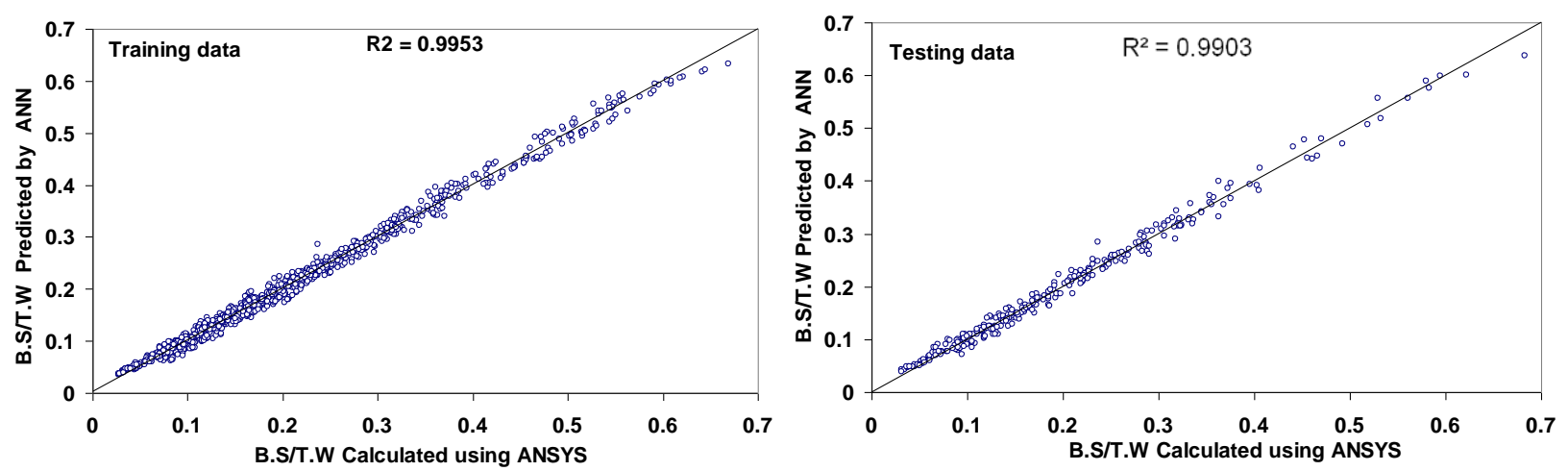

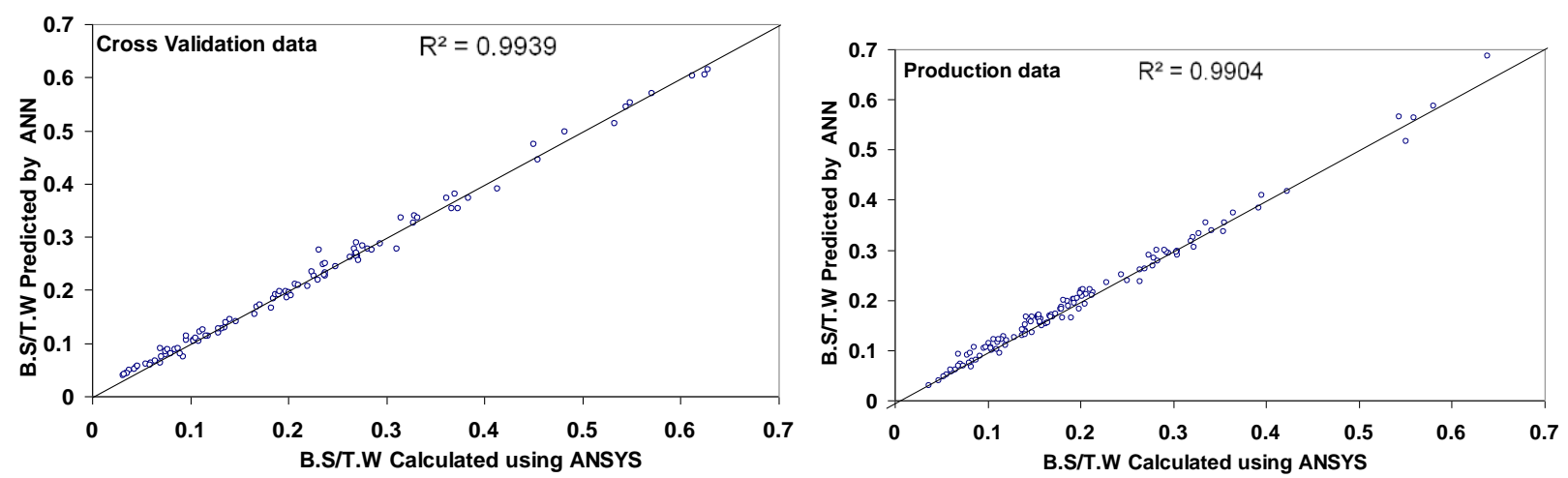

(a)
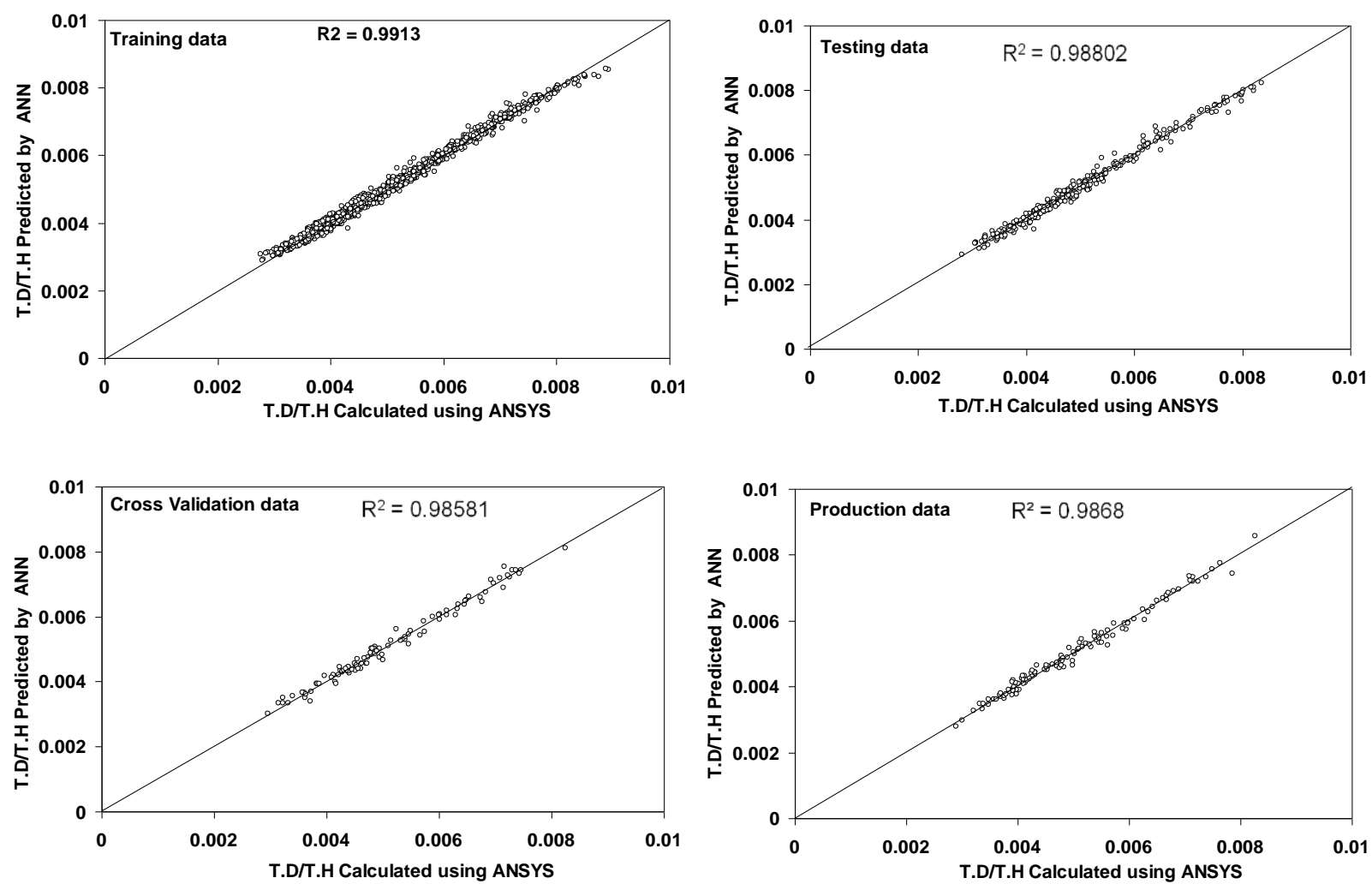

(b)

Fig. (9) Comparison of results of pushover analysis using ANSYS and ANN (MP-CG-11-15-2) for: a) B.S/T.W; b) T.D/T.H

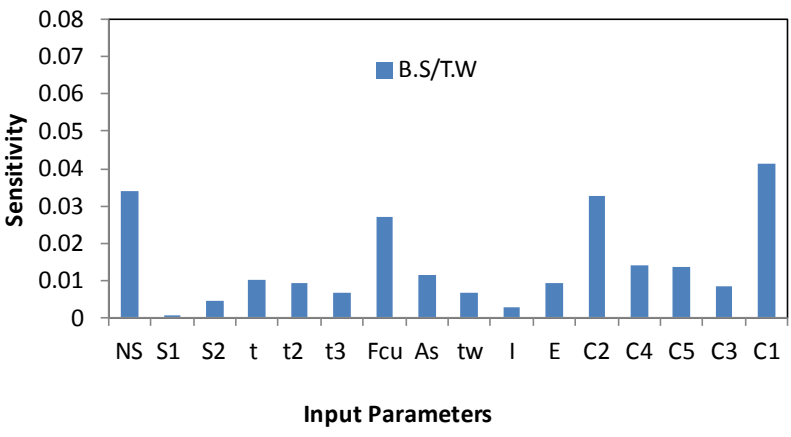

(a)

Fig. (10) Sensitivity of (MP-CG-11-15-2)network to input parameters for: a) B.S/T.W; b) T.D/T.H 


\begin{tabular}{lllll}
$-\square$ C1 & $\checkmark$ C2 & $\triangleleft$ C3 & $-\times-$ C4 & $\ominus$ C5 \\
$\square$ FE-C1 & $\diamond$ FE-C2 & $\triangle$ FE-C3 & $\times$ FE-C4 & $\bullet$ FE-C5 \\
\hline
\end{tabular}
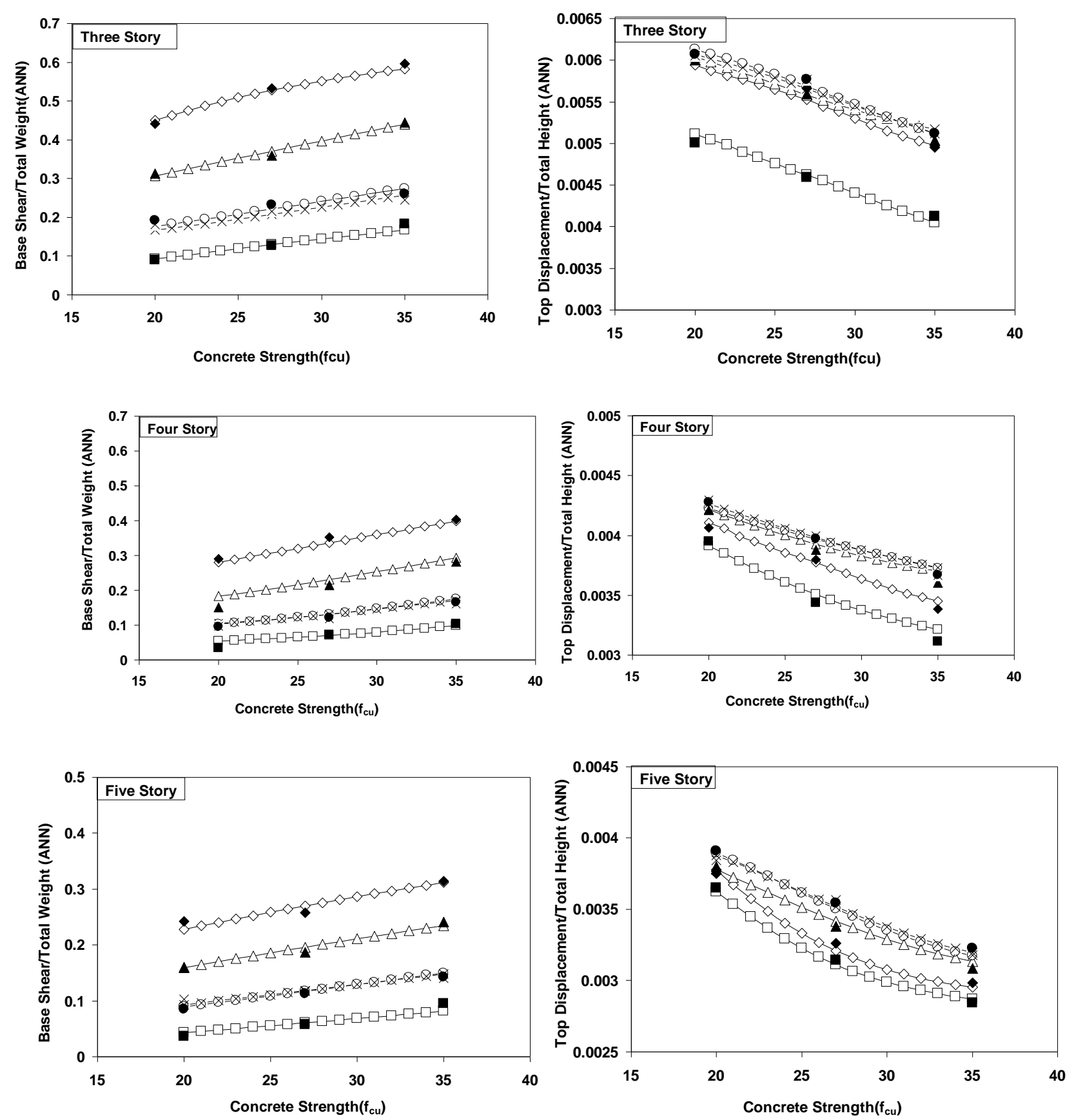

Fig.(11).Effect of Concrete Strength ( $\left.f_{c u}\right)$ on (B.S/T.W) and (T.D/T.H) 


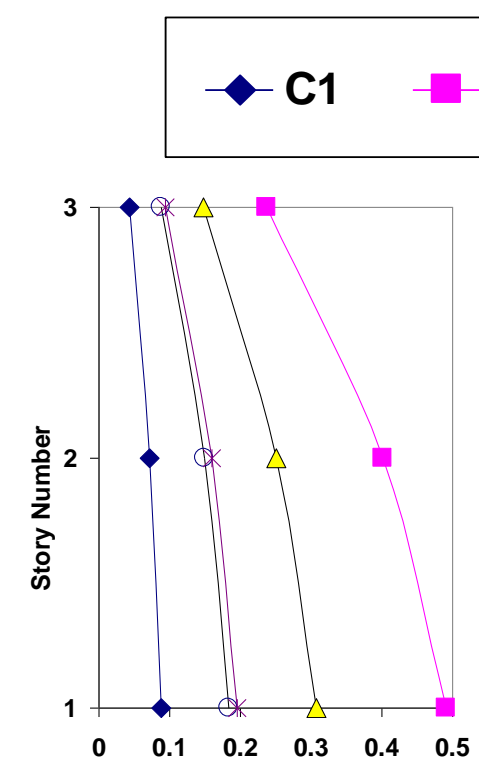

Floor shear / Total Weight (F.S/T.W)

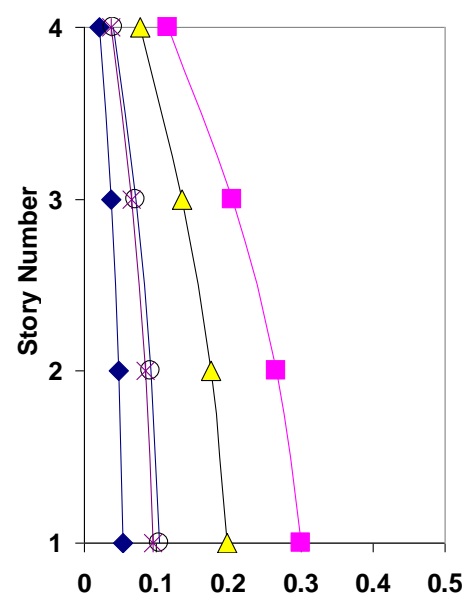

Floor shear / Total Weight (F.S/T.W)

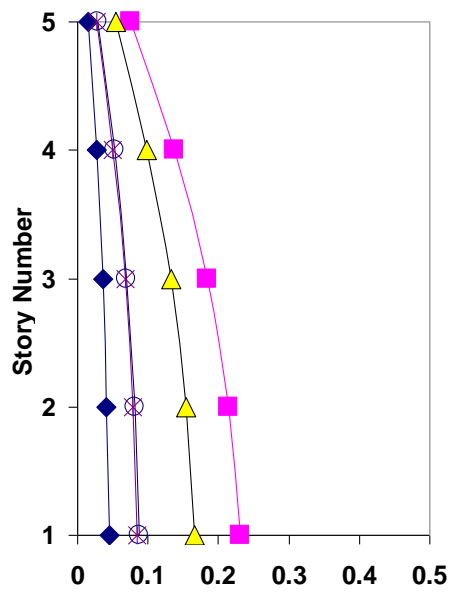

Floor shear / Total Weight (F.S/T.W)

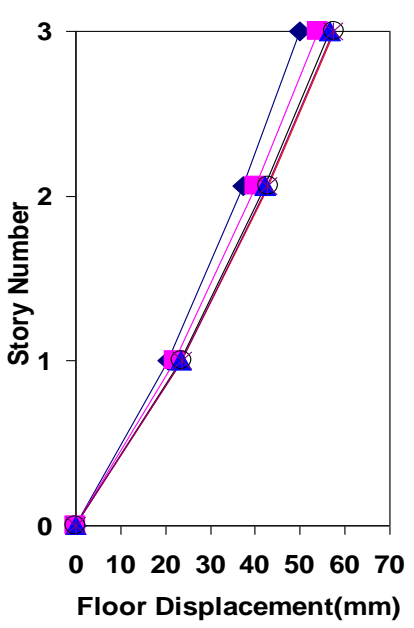

a)Three story frame

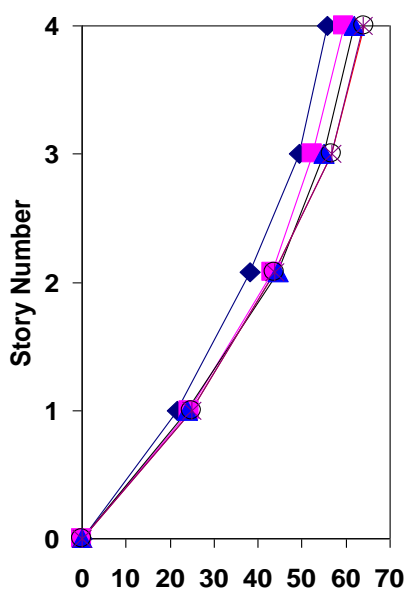

Floor Displacement (mm)

b)Four story frame
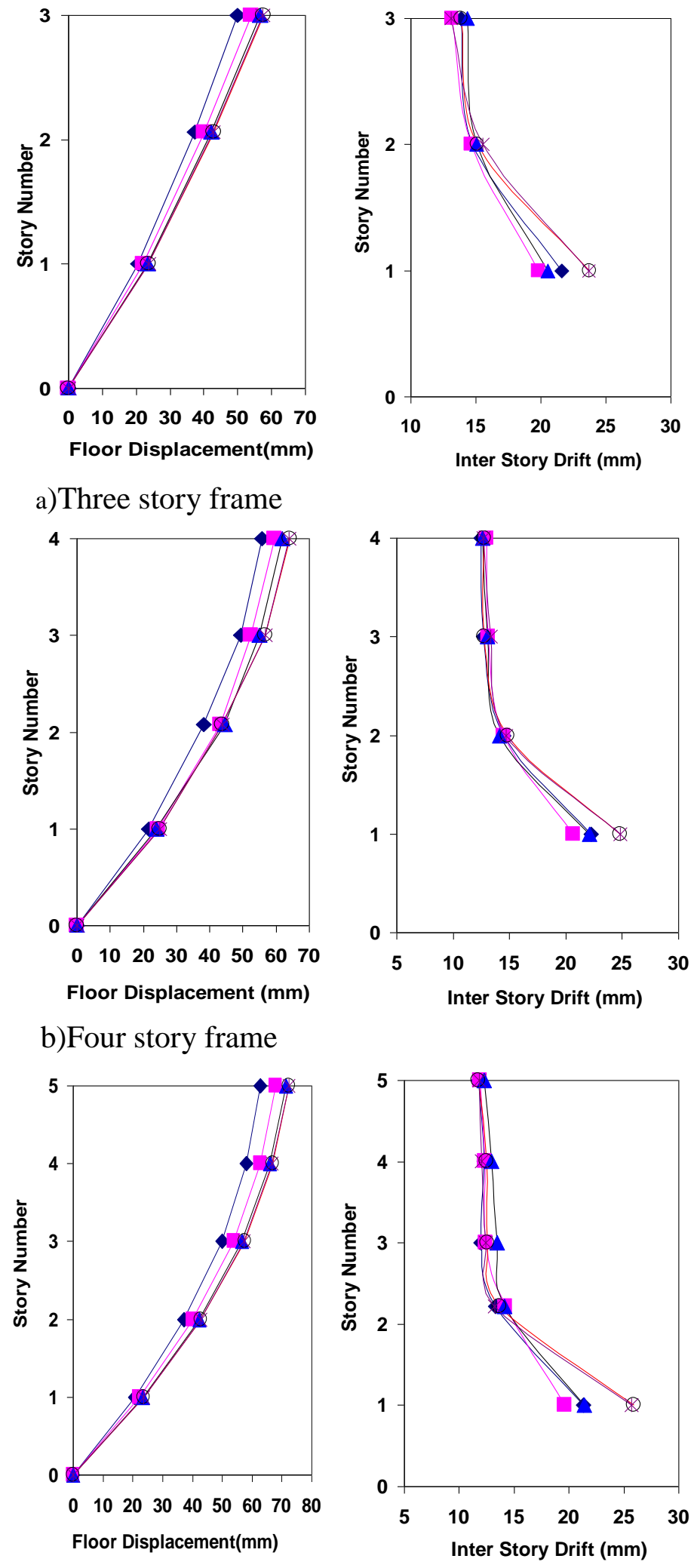

c)Five story frame Fig.

(12) Results of pushover analysis for different frames for $f_{c u}=27.5 \mathrm{MPa}$ 

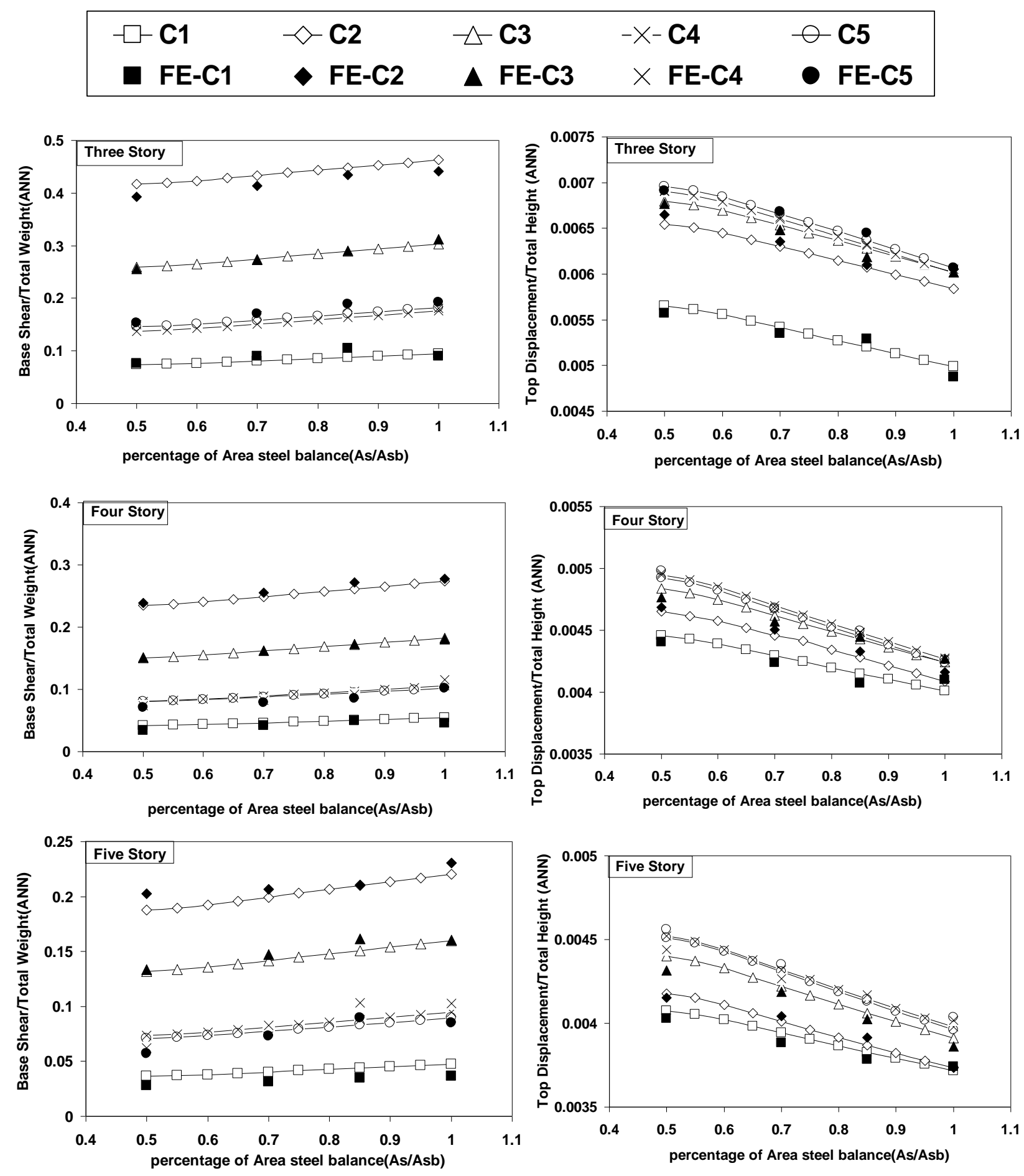

Fig.(13). Effect Area of steel (AS) on (B.S/T.W) and (T.D/T.H) 


\begin{tabular}{|lllll|}
$-\square-$ C1 & $\diamond$ C2 & $\triangleleft$ C3 & $-\times-$ C4 & $\ominus$ C5 \\
$\square$ FE-C1 & $\diamond$ FE-C2 & $\triangle$ FE-C3 & $\times$ FE-C4 & $\bullet$ FE-C5 \\
\hline
\end{tabular}
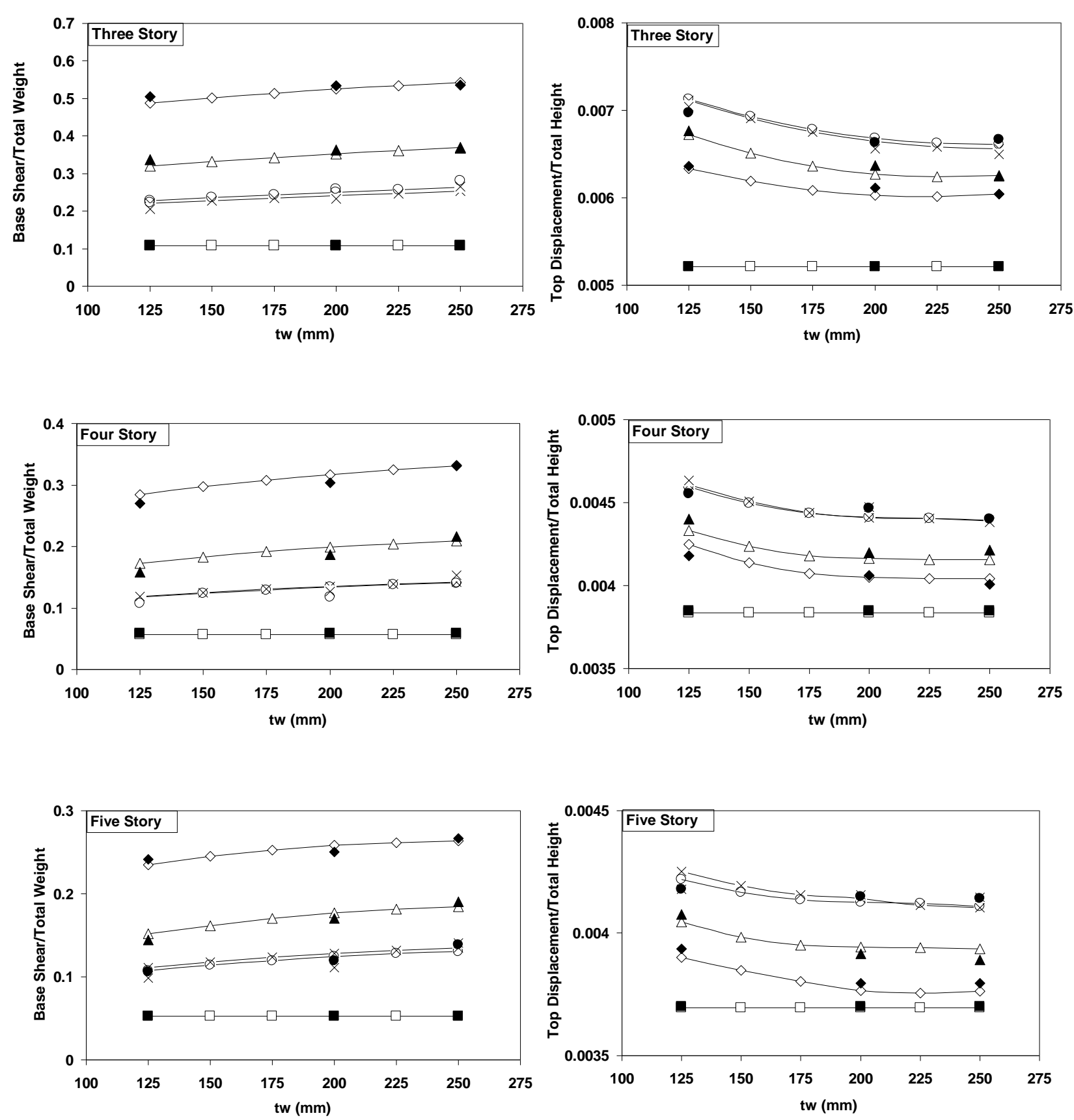

Fig.(14). Effect of wall thickness on (B.S/T.W) and (T.D/T.H) 
Table 1. ANN Input parameters

\begin{tabular}{lll}
\hline parameter & Definition & Range \\
\hline $\mathrm{Ns}$ & Number of stories & $3,4,5$ \\
$\mathrm{~S} 1$ & Short span & $3.0,3.5,4.0 \mathrm{~m}$ \\
$\mathrm{~S} 2$ & Long span & $5.0,6.0,7.0 \mathrm{~m}$ \\
$\mathrm{t}$ & Height of beam & $0.5,0.6,0.7 \mathrm{~m}$ \\
$\mathrm{t} 2$ & Thickness of column 2 & $0.9,1.0,1.1 \mathrm{~m}$ \\
$\mathrm{t} 3$ & Thickness of column 3 & $0.5,0.6,0.7 \mathrm{~m}$ \\
$\mathrm{f}_{\mathrm{cu}}$ & Strength of concrete & $20,27.5,35 \mathrm{~N} / \mathrm{mm}^{2}$ \\
$\mathrm{~A}_{\mathrm{s}}$ & Percentage of Area of steel / balanced & $0.5,0.7,1.0 *$ \\
& steel & \\
$\mathrm{t}_{\mathrm{w}}$ & Width of brick wall & $0.125,0.25 \mathrm{~m}$ \\
$\mathrm{I}, \mathrm{E}$ & Frame location (Interior or Exterior) & I and E \\
$\mathrm{C}$ & Configuration of frames (Fig.1.b) & $\mathrm{C} 1, \mathrm{C} 2, \mathrm{C} 3, \mathrm{C} 4, \mathrm{C} 5$ \\
\hline
\end{tabular}

*For training phase only and not for practical applications

Table2. Dimensions and Reinforcement of different cases

\begin{tabular}{|c|c|c|c|c|c|c|c|c|c|c|c|}
\hline \multirow{3}{*}{ Element } & \multirow{3}{*}{$\begin{array}{l}\text { Paramet } \\
\text { er }\end{array}$} & \multicolumn{3}{|c|}{ Case1 $(\mathrm{S} 1=3 \mathrm{~m}, \mathrm{~S} 2=5 \mathrm{~m})$} & \multicolumn{3}{|c|}{ Case $2(\mathrm{~S} 1=3.5 \mathrm{~m}, \mathrm{~S} 2=6 \mathrm{~m})$} & \multicolumn{3}{|c|}{ Case3 $(\mathrm{S} 1=4 \mathrm{~m}, \mathrm{~S} 2=7 \mathrm{~m})$} & \multirow{3}{*}{ Stirrups } \\
\hline & & \multicolumn{2}{|c|}{$\begin{array}{l}\text { Dimension, } \\
\mathrm{m}\end{array}$} & \multirow[t]{2}{*}{ Rft } & \multicolumn{2}{|c|}{$\begin{array}{l}\text { Dimension, } \\
\mathrm{m}\end{array}$} & \multirow[t]{2}{*}{$\mathrm{Rft}$} & \multicolumn{2}{|c|}{$\begin{array}{l}\text { Dimension, } \\
\mathrm{m}\end{array}$} & \multirow[t]{2}{*}{$\mathrm{Rft}$} & \\
\hline & & $\mathrm{b}$ & $\mathrm{t}$ & & b & $\mathrm{t}$ & & $\mathrm{b}$ & $\mathrm{t}$ & & \\
\hline \multirow{3}{*}{ Columns } & a1 & 0.25 & 0.40 & $6 \phi 16$ & 0.25 & 0.40 & $6 \phi 16$ & 0.25 & 0.40 & $6 \phi 16$ & $\square 8 @ 15 \mathrm{~cm}$ \\
\hline & a2 & 0.25 & 0.90 & $10 \phi 16$ & 0.25 & 1.00 & $10 \phi 18$ & 0.25 & 1.10 & $10 \phi 20$ & $\square 8 @ 15 \mathrm{~cm}$ \\
\hline & a3 & 0.25 & 0.50 & $6 \phi 16$ & 0.25 & 0.60 & $6 \phi 16$ & 0.25 & 0.70 & $8 \phi 14$ & $\square 8 @ 15 \mathrm{~cm}$ \\
\hline \multirow{8}{*}{ Beams } & St1 & \multirow{8}{*}{0.25} & \multirow{8}{*}{0.50} & $\begin{array}{c}3 \phi 22 \\
+3 \phi 25 \\
\end{array}$ & \multirow{8}{*}{0.25} & \multirow{8}{*}{0.60} & $\begin{array}{r}3 \phi 25 \\
+3 \phi 28 \\
\end{array}$ & \multirow{8}{*}{0.25} & \multirow{8}{*}{0.70} & $6 \phi 28$ & \multirow{8}{*}{$\square 8 @ 15 \mathrm{~cm}$} \\
\hline & St2 & & & $3 \phi 16$ & & & $3 \phi 18$ & & & $3 \phi 18$ & \\
\hline & St3 & & & $3 \phi 16$ & & & $3 \phi 18$ & & & $3 \phi 18$ & \\
\hline & St4 & & & $2 \phi 16$ & & & $2 \phi 16$ & & & $2 \phi 16$ & \\
\hline & St5 & & & $2 \phi 16$ & & & $2 \phi 16$ & & & $2 \phi 16$ & \\
\hline & St6 & & & $3 \phi 22$ & & & $3 \phi 25$ & & & $3 \phi 28$ & \\
\hline & St7 & & & $3 \phi 25$ & & & $3 \phi 28$ & & & $3 \phi 28$ & \\
\hline & St8 & & & $2 \phi 12$ & & & $2 \phi 12$ & & & $2 \phi 12$ & \\
\hline
\end{tabular}


Table 3. Performance of different back-propagation Neural Network for (B.S/T.W) and (T.D/T.H)

\begin{tabular}{|c|c|c|c|c|c|c|c|c|}
\hline \multirow[b]{2}{*}{$\begin{array}{c}\text { Back } \\
\text { Propagatio } \\
\text { n Methods }\end{array}$} & \multirow{2}{*}{$\begin{array}{c}\text { NO. of } \\
\text { neurons } \\
\text { per } \\
\text { hidden } \\
\text { layer }\end{array}$} & \multirow[b]{2}{*}{$\begin{array}{c}\text { ANN } \\
\text { Structure }\end{array}$} & \multicolumn{3}{|c|}{ MSE } & \multicolumn{3}{|c|}{$\mathbf{R}^{2} \%$} \\
\hline & & & $\begin{array}{l}\text { Trainin } \\
\mathbf{g}\end{array}$ & Testing & $\begin{array}{c}\text { Cross } \\
\text { validatio } \\
\mathbf{n}\end{array}$ & $\begin{array}{l}\text { Trainin } \\
\text { g }\end{array}$ & Testing & $\begin{array}{c}\text { Cross } \\
\text { validation }\end{array}$ \\
\hline \multicolumn{9}{|c|}{ (B.S/T.W) } \\
\hline GFF-CG & 50 & $11-50-2$ & 0.00016 & 0.00018 & 0.00019 & 99.165 & 99.120 & 99.200 \\
\hline GFF-CG & 50 & $11-50-50-2$ & 0.00025 & 0.00028 & 0.00031 & 98.933 & 98.645 & 99.022 \\
\hline GFF-M & 85 & $11-85-2$ & 0.00137 & 0.00146 & 0.00161 & 94.910 & 94.140 & 95.559 \\
\hline GFF-M & 85 & $11-85-85-2$ & 0.00116 & 0.00120 & 0.00130 & 95.730 & 95.130 & 96.319 \\
\hline GFF-Q & 80 & $11-80-2$ & 0.00148 & 0.00153 & 0.00201 & 94.180 & 93.188 & 95.136 \\
\hline GFF-Q & 80 & $11-80-80-2$ & 0.00126 & 0.00135 & 0.00146 & 94.610 & 93.761 & 95.734 \\
\hline GR-CG & 30 & 11-30-2 & 0.00127 & 0.00138 & 0.00149 & 94.696 & 93.688 & 95.697 \\
\hline GR-CG & 35 & $11-35-35-2$ & 0.00045 & 0.00048 & 0.00045 & 98.125 & 97.788 & 98.702 \\
\hline GR-M & 30 & $11-30-2$ & 0.00122 & 0.00135 & 0.00145 & 93.544 & 92.770 & 93.110 \\
\hline GR-M & 40 & $11-40-40-2$ & 0.00111 & 0.00122 & 0.00146 & 95.800 & 95.540 & 96.133 \\
\hline GR-Q & 30 & $11-30-2$ & 0.00165 & 0.00170 & 0.00181 & 93.047 & 92.187 & 93.803 \\
\hline GR-Q & 35 & $11-35-35-2$ & 0.00115 & 0.00121 & 0.00145 & 95.258 & 94.454 & 96.292 \\
\hline MP-CG & 15 & $11-15-2$ & 0.00012 & 0.00014 & 0.00016 & 99.534 & 99.368 & 99.580 \\
\hline MP-CG & 20 & $11-20-20-2$ & 0.00015 & 0.00017 & 0.00019 & 99.373 & 99.225 & 99.483 \\
\hline MP-M & 15 & $11-15-2$ & 0.00084 & 0.00092 & 0.00103 & 96.480 & 95.698 & 97.252 \\
\hline MP-M & 20 & $11-20-20-2$ & 0.00086 & 0.00096 & 0.00107 & 96.690 & 96.090 & 97.215 \\
\hline MP-Q & 30 & $11-30-2$ & 0.00075 & 0.00082 & 0.00091 & 96.875 & 96.184 & 97.584 \\
\hline MP-Q & 60 & $11-60-60-2$ & 0.00302 & 0.00305 & 0.00340 & 90.585 & 88.892 & 92.576 \\
\hline PCA-CG & 35 & $11-35-2$ & 0.00982 & 0.01010 & 0.01060 & 58.494 & 59.300 & 59.829 \\
\hline PCA-CG & 25 & $11-25-25-2$ & 0.01095 & 0.01071 & 0.01180 & 53.715 & 50.634 & 56.371 \\
\hline PCA-M & 55 & $11-55-2$ & 0.01700 & 0.01597 & 0.01770 & 29.300 & 29.300 & 30.882 \\
\hline PCA-M & 40 & $11-40-40-2$ & 0.01259 & 0.01226 & 0.01370 & 53.400 & 48.600 & 44.600 \\
\hline PCA-Q & 60 & $11-60-2$ & 0.02051 & 0.01938 & 0.02160 & 57.100 & 52.400 & 50.000 \\
\hline PCA-Q & 25 & $11-25-25-2$ & 0.01790 & 0.01500 & 0.02410 & 56.700 & 58.000 & 54.500 \\
\hline \multicolumn{9}{|c|}{ (T.D/T.H) } \\
\hline GFF-CG & 50 & 11 & 0.00081 & 0.00 & 0.00 & 95.200 & 95.050 & 95.380 \\
\hline GFF-CG & 50 & $11-50-50-2$ & 0.00096 & 0.00086 & 0.00074 & 95.980 & 96.520 & 96.935 \\
\hline GFF-M & 85 & $11-85-2$ & 0.00254 & 0.00190 & 0.00155 & 90.520 & 91.100 & 91.457 \\
\hline GFF-M & 85 & $11-85-85-2$ & 0.00218 & 0.00183 & 0.00157 & 91.310 & 92.010 & 92.490 \\
\hline GFF-Q & 80 & $11-80-2$ & 0.00317 & 0.00269 & 0.00223 & 88.909 & 90.187 & 91.290 \\
\hline GFF-Q & 80 & $11-80-80-2$ & 0.00321 & 0.00265 & 0.00202 & 89.170 & 89.640 & 91.170 \\
\hline GR-CG & 20 & $11-20-2$ & 0.00306 & 0.00244 & 0.00208 & 89.097 & 90.046 & 91.452 \\
\hline GR-CG & 35 & $11-35-35-2$ & 0.00158 & 0.00142 & 0.00103 & 94.363 & 94.685 & 95.719 \\
\hline GR-M & 20 & $11-20-2$ & 0.00317 & 0.00302 & 0.00284 & 87.520 & 88.010 & 88.594 \\
\hline GR-M & 60 & $11-60-60-2$ & 0.00330 & 0.00255 & 0.00270 & 87.980 & 88.600 & 89.200 \\
\hline GR-Q & 30 & $11-30-2$ & 0.00285 & 0.00266 & 0.00250 & 86.240 & 86.800 & 87.420 \\
\hline GR-Q & 55 & $11-55-55-2$ & 0.00520 & 0.00432 & 0.00449 & 87.000 & 88.770 & 88.896 \\
\hline MP-CG & 15 & $11-15-2$ & 0.00024 & 0.00032 & 0.00034 & 99.138 & 98.802 & 98.581 \\
\hline MP-CG & 15 & $11-15-15-2$ & 0.00071 & 0.00072 & 0.00058 & 97.461 & 97.940 & 97.649 \\
\hline MP-M & 15 & $11-15-2$ & 0.00252 & 0.00206 & 0.00143 & 91.020 & 92.302 & 94.235 \\
\hline MP-M & 15 & $11-15-15-2$ & 0.00244 & 0.00192 & 0.00155 & 91.301 & 92.845 & 94.689 \\
\hline MP-Q & 30 & $11-30-2$ & 0.00238 & 0.00193 & 0.00127 & 91.531 & 92.809 & 94.889 \\
\hline MP-Q & 55 & $11-55-55-2$ & 0.00367 & 0.00313 & 0.00252 & 83.100 & 86.000 & 89.100 \\
\hline PCA-CG & 20 & 11-20-2 & 0.00748 & 0.00682 & 0.00707 & 73.260 & 74.491 & 70.721 \\
\hline PCA-CG & 20 & $11-20-20-2$ & 0.00792 & 0.00722 & 0.00856 & 71.705 & 73.198 & 69.500 \\
\hline PCA-M & 60 & $11-60-2$ & 0.00787 & 0.00666 & 0.00900 & 73.700 & 75.206 & 71.300 \\
\hline PCA-M & 20 & $11-20-20-2$ & 0.00887 & 0.00792 & 0.00980 & 68.295 & 70.455 & 65.300 \\
\hline PCA-Q & 70 & 11-70-2 & 0.00646 & 0.00609 & 0.00684 & 74.623 & 77.235 & 74.600 \\
\hline PCA-Q & 40 & $11-40-40-2$ & 0.01004 & 0.00892 & 0.03174 & 78.500 & 75.000 & 76.000 \\
\hline
\end{tabular}


List of Abbreviation

$\begin{array}{ll}\text { ANNs } & \text { Artificial neural networks } \\ \mathrm{RC} & \text { Reinforced Concrete } \\ \mathrm{t}_{\mathrm{w}} & \text { masonry walls with thickness } \\ \mathrm{E}_{\mathrm{s}} & \text { Steel modulus of elasticity } \\ \mathrm{F}_{\mathrm{cu}} & \text { compressive strength of concrete } \\ \mathrm{F}_{\mathrm{tu}} & \text { ultimate tensile strength of steel } \\ v & \text { Poisson's ratio } \\ \mathrm{f}_{\mathrm{sy}} & \text { yield strength of steel } \\ (\mathrm{B} . \mathrm{S} / \mathrm{T} . \mathrm{W}) & \text { base shear over total weight } \\ (\mathrm{T} . \mathrm{D} / \mathrm{T} . \mathrm{H}) . & \text { top displacement over total height } \\ f(\mathrm{t}) & \text { Transfer function } \\ S X & \text { The normalized value } \\ R^{2} & \text { coefficient of multiple determinations } \\ M S E & \text { the mean square error } \\ \mathrm{GFF} & \text { Generalized Feed Forward network } \\ \mathrm{GR} & \text { General Recurrent network } \\ \mathrm{MP} & \text { Multilayer Perceptron network } \\ \mathrm{PCA} & \text { Principal Component Analysis network } \\ \mathrm{M} & \text { Momentum learning functions. } \\ \mathrm{Q} & \\ \mathrm{CG} & \text { Quick-propagation learning functions. } \\ (\mathrm{FE}) & \text { Conjugate Gradient learning functions. } \\ & \text { finite element }\end{array}$

